\title{
A Retrospective Study Assessing The Frequency Of Patient's Requiring TPA/LSA During Orthodontic Therapy - An Institutional Study
}

Research Article

\author{
Neha Sharma $\mathrm{M}^{1}$, Remmiya Mary Varghese ${ }^{2 *}$ L. Leelavathi ${ }^{3}$
}

${ }^{1}$ Saveetha Dental College And Hospitals, Saveetha Institute Of Medical and Technical Sciences, Saveetha University, Chennai, 600050, India.

${ }^{2}$ Senior Lecturer, Department of Orthodontics, Saveetha Dental College and Hospitals, Saveetha Institute Of Medical And Technical Sciences, Saveetha University, Chennai, India.

${ }^{3}$ Senior Lecturer, Department of Public Health Dentistry, Saveetha Dental College and Hospitals, Saveetha Institute Of Medical And Technical Sciences, Saveetha University, Chennai, India.

\section{Abstract}

TPA, also known as Transpalatal Arch is used as an adjunctive appliance during orthodontic treatment to control anchorage in the vertical, transverse and sagittal (antero-posterior) dimensions. Its many uses have included molar anchorage, space maintenance, and retention after rapid maxillary expansion. TPAs have great versatility, acting as a stand-alone appliance or as an adjunct to fixed appliances. Hence the aim of this study is to assess the number of patients who required TPA/LSA during an orthodontic therapy. Retrospective cross sectional study was carried out and the case records of patients requiring TPA/LSA was collected by reviewing patient records and analyzing the data of patients between June 2019- April 2020. The data was collected and subjected to Chi square test for statistical analysis and correlation using the SPSS software. The findings of this study showed female predilection with a percentage of $53 \%$ and males with a percentage of $47 \%$. It also revealed that the prevalence of patients requiring TPA during an orthodontic therapy was $32 \%$ and LSA was $26 \%$. This study shows that $32.24 \%$ of the patients required TPA and $25.75 \%$ of the patients also required LSA during an orthodontic treatment and this was found to be statistically significant.

Keywords: Transpalatal Arch; Lingual Stabilising Arch; Anchorage; Orthodontic Therapy.

\section{Introduction}

The transpalatal arch (TPA) is a stainless steel wire connecting the maxillary molars during fixed appliance orthodontic treatment to assist with anchorage reinforcement [2]. The maxillary first molars are often rotated with the mesiobuccal cusp displaced in a palatal direction. The consequences of the malposition are that the tooth occupies excessive space in the dental arch and that the buccal cusps occlude with a tendency to a Class II molar relationship [5]. Malocclusions require precise extraction protocol to avoid excessive space [11]. Maximum anchorage, when the first molars maintain their position and do not move into the extraction site, often is desirable in the maxillary arch [36]. A low clinical failure rate is a necessary clinical criterion of paramount importance [27]. The LSA or Lingual Stabilizing Arch exerts a continuous force since it is cemented 24 hours a day so the patient cannot remove it. One of its most important functions is as a space maintainer when there is premature loss of deciduous teeth. It helps prevent mo- lar mesialization. An expansive, horizontal force from the palatal arch would more rapidly affect the buccal crown tipping than the root movement of the anchorage tooth [12]. Early recognition and appropriate therapy can ameliorate the consequences [33]. TPA stops continued vertical descent of the upper buccal teeth and therefore stops maxillary alveolar vertical growth [34]. The TPA can either be made from stainless steel round wire of proper gauge to fit into the molar sheaths or a preformed TPA may be chosen [25].

It has been stated that TPAs effectively correct the crossbite without any side effects [13]. Additionally, during molar derotation, transseptal fibers could potentially move deciduous molars or premolars buccally, potentially offering further increases in dental arch width and perimeter [24]. Another version of the TPA is the one with an acrylic button (which has sometimes been named as vertical holding appliance or VHA) that is supposed to use the tongue pressure to restrain the normal descent of molars during

*Corresponding Author:
Remmiya Mary Varghese,
Senior Lecturer, Department of Orthodontics, Saveetha Dental College and Hospitals, Saveetha Institute Of Medical And Technical Sciences, Saveetha University, Chennai, India.
E-mail: remmiyav.sdc@saveetha.com

Received: July 27, 2020

Accepted: August 23, 2020

Published: August 30, 2020

Citation: Neha Sharma M, Remmiya Mary Varghese, L. Leelavathi. A Retrospective Study Assessing The Frequency Of Patient's Requiring TPA/LSA During Orthodontic Therapy - An Institutional Study. Int J Dentistry Oral Sci. 2020;S5:02:0028:153-158. doi: http://dx.doi.org/10.19070/2377-8075-SI02-050028

Copyright: Remmiya Mary Varghese ${ }^{\circ} 2020$. This is an open-access article distributed under the terms of the Creative Commons Attribution License, which permits unrestricted use, distribution and reproduction in any medium, provided the original author and source are credited. 
Figure 1. Occlusal view of maxillary arch with Transpalatal arch.

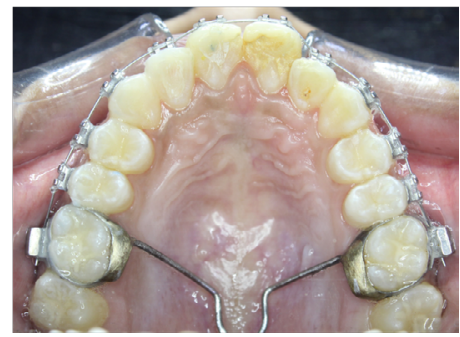

Figure 2. Occlusal view of Mandibular arch with Lingual Stabilizing Arch.

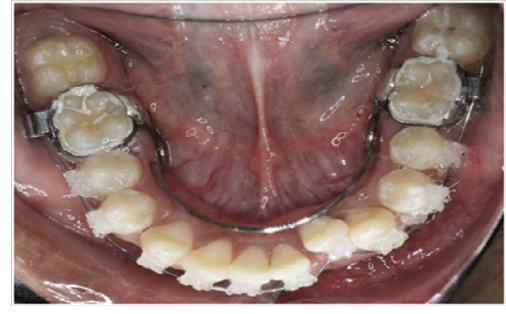

the orthodontic treatment and to be beneficial in controlling the vertical development of the maxillary molars during their eruption $[29,35]$.

With the current widespread use of bone anchorage devices, which provide absolute anchorage, it has become even more important to know which of our classical devices are able to provide sufficient anchorage to consider them or not as a treatment option. Hence the aim of our study is to assess the number of patients who require TPA/LSA during an orthodontic treatment.

\section{Materials and Methods}

This is a retrospective study regarding patients requiring TPA/ LSA during orthodontic therapy, who have visited Saveetha Dental College and Hospitals in between June 2019- April 2020. The approval for this study setting was obtained from the Institution Ethics Board. The sample size of 1301 patients in which sampling bias was minimized with the verification of photos. The study was reviewed by two reviewers and it was cross verified. Inclusion criteria- patients requiring TPA/LSA; Exclusion criteria- incomplete record in the system. The case records of patients requiring TPA/ LSA was collected by reviewing patient records and analyzing the data of 86000 patients. The data of these patients was collected and tabulated. It included parameters - Patients ID, Age, Gender, patients requiring TPA, LSA and not applicable. Age was categorized into 9-15 years, 15-20 years, 20-30 years and patients more than 30 years. After further verification by an external reviewer, it was imported to SPSS software by IBM for statistical analysis. Percentage, mean, standard deviation, frequency of parameters were employed in the analysis. Chi square test was used to detect the significance between age, gender, severity of fluorosis and teeth involving fluorosi. $\mathrm{P}$ value less than 0.05 was considered to be statistically significant.

\section{Result And Discussion}

The findings of this study showed $47 \%$ of the study population were males and $53 \%$ of the patients were females [Graph 1]. It was found that $37 \%$ of the patients were $21-30$ years old , $32.5 \%$ were between $16-20$ years , 26\% were between $9-15$ years and only
$7 \%$ were more than 30 years old [Graph 2]. When checked for the frequency of patients requiring TPA and LSA, it was found that 424 patients [32\%] out of 1301 patients requiring TPA [ Graph 3] and 335 patients [26\%] required LSA [Graph 4]. On doing chi square test; between age and requirement of TPA, it was found that highest number of patients requiring TPA [12\%] belonged to the age group 21-30 years [Graph 5]; between age and requirement of LSA, it was found that the highest number of patients requiring LSA [9.5\%] were again between 21-30 years [Graph 6]. On correlating gender and requirement of TPA, it was found that $233[18 \%]$ females and 191 [14.5\%] males required TPA [Graph 7]. On correlating gender and LSA, it was found that 195 [15\%] females and $140[11 \%]$ males required LSA during an orthodontic therapy [Graph 8]. Although none of the above findings were found to be statistically significant. On doing Chi square test between requirement of TPA along with LSA, it was found that among the patients requiring TPA, almost 25\% of them also required LSA [Graph 9]. This was found to be statistically significant $\mathrm{p}$ value $0.0<0.05$.

Orthodontic treatment involves the application of forces that are continuous in activity on as many areas of the dentition as possible and working in the direction in which the teeth are to move [7]. The binding relationship between orthodontic treatment and facial esthetics has made the facial outline an important guideline for the treatment planning [18]. The fundamentals of orthodontics is that teeth move through the alveolar bone when adequate forces are delivered [17]. Orthodontic extrusion of the tooth can be done by several ways with several advantages and disadvantages [11]. The TPA can be used as an adjunct during orthodontic treatment to help control the movement of the maxillary first molars in 3 dimensions [32], including producing molar rotation and uprighting, maintaining transverse dimensions posteriorly during treatment and maintaining leeway spaces during the transition of the dentition [28]. Other devices such as Mini screws have been successfully used as temporary anchorage devices for producing various tooth movements [14]. It is difficult to achieve the appropriate moment-to-force ratio when using a transpalatal arch [19], because each attempt to adjust the magnitude of the moment by modifying the torque bends automatically influences the lateral force [3]. The wire is bent to adapt to the palate. Six bendings may be required and three of them are obligatory (to adapt 
Graph 1. Bar graph representing the frequency distribution of requirement of TPA/LSA among different genders. $\mathrm{X}$ axis denotes the gender of the patients and $\mathrm{Y}$ axis denotes the number of patients undergoing orthodontic treatment. Majority of the patients who required TPA/LSA were males followed by females.

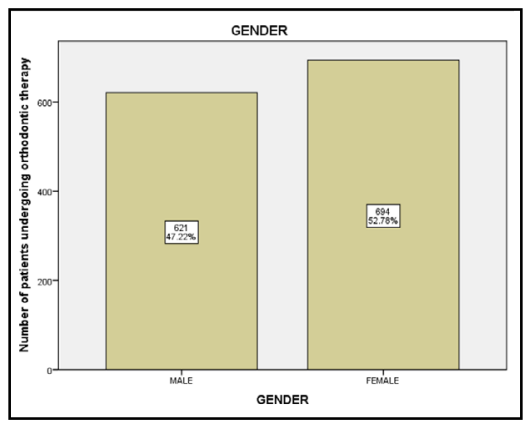

Graph 2. Bar graph representing the frequency distribution of requirement of TPA/LSA among different Age groups of patients. $\mathrm{X}$ axis denotes the age of the patients and $\mathrm{Y}$ axis denotes the number of patients undergoing orthodontic treatment. Majority of the patients who required TPA/LSA were in the age group of 21-30 years followed by patients in the age group of 16-20 years and the rest were in the age group of 9-15 years old..

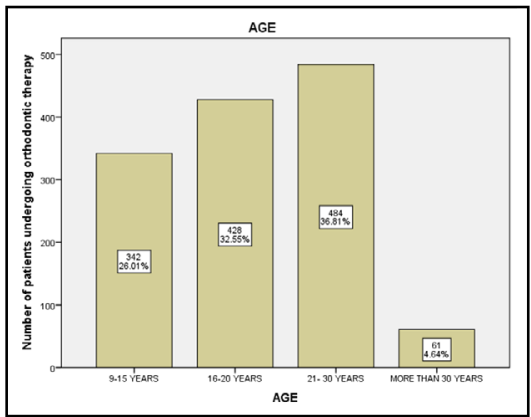

Graph 3. Bar graph representing the frequency distribution of requirement of TPA among the patients. X-axis is the number of patients requiring TPA and y-axis is the number of patients .Majority of the patients did not require TPA which is followed by the number of patients requiring TPA.

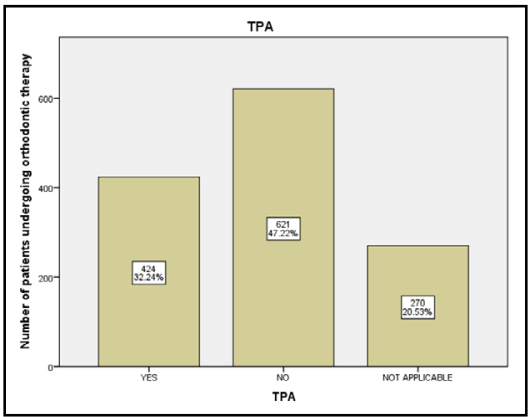

Graph 4. Bar graph representing the frequency distribution of patients requiring LSA among the total patients. X axis denotes the number of patients requiring LSA and $\mathrm{Y}$ axis is the number of patients undergoing orthodontic therapy. Majority of the patients did not require LSA which is followed by patients requiring LSA.

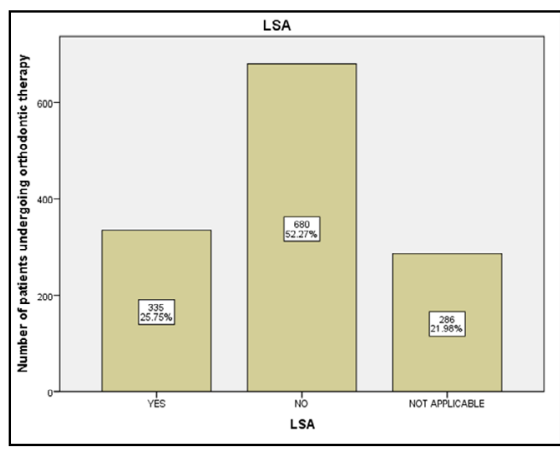

to the form of the palate, to adapt to the torque of the molars, and to adapt to the rotation of the molars [30]. The other three are needed in some of the cases: bending the end of the TPA, which will be held with the pliers, so that it does not traumatise the palatal mucosa and does not irritate the tongue [22]. A study shows that presence of a TP A induces only minor changes in the dental and periodontal stress distributions [4]. A previous study states that TPA is not a convenient maximum anchorage device and does not provide a significant protection on the anteroposterior position, inclination, and extrusion of the maxillary first molars for canine retraction following extraction [16]. Use of TPA in mixed dentition followed by fixed appliances was effective in 
Graph 5. Bar graph represents the association between Age and the number of patients requiring TPA .X-axis represents the age of the patients and Y-axis represents the number of patients requiring TPA during orthodontic therapy. Among the total study population, the majority of the patients requiring TPA belonged to the age group of 21-30 years, followed by patients in the age group 16-20 years and 9-15 years age group. Chi square test, p value $-0.101(>0.05)$ hence, statistically not significant.

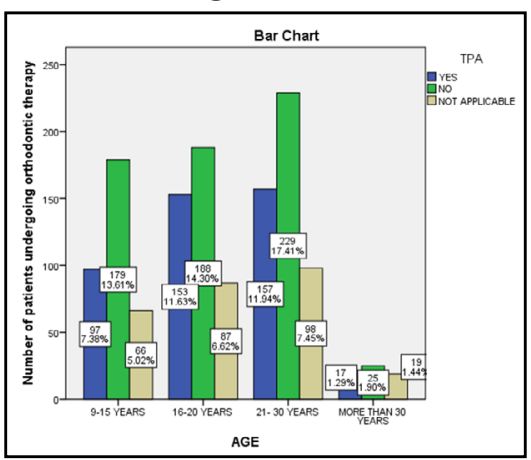

Graph 6. Bar graph represents the association between Age and the number of patients requiring LSA .X-axis represents the age of the patients and Y-axis represents the number of patients requiring LSA during orthodontic therapy. Among the total study population, the majority of the patients requiring LSA belonged to the age group of 21-30 years, followed by patients in the age group 16-20 years and 9-15 years age group. Chi square test. $P$ value-0.167 $(>0.050)$, Hence statistically not significant.

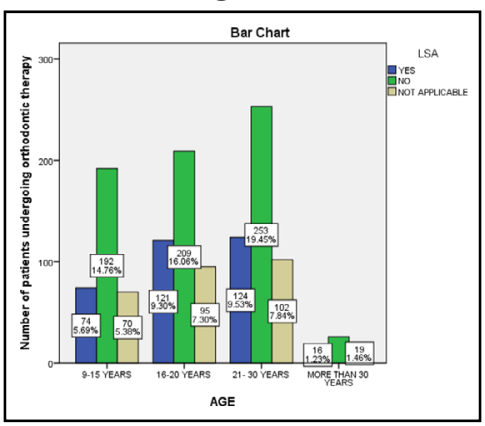

Graph 7. Bar graph represents the association between gender and the number of patients requiring TPA .X-axis represents the gender of the patients and Y-axis represents the number of patients requiring TPA during orthodontic therapy. Among the total study population, the majority of the patients requiring TPA were females as compared to male patients.

Chi square test,p value- $0.535>(0.05)$ hence, statistically not significant.

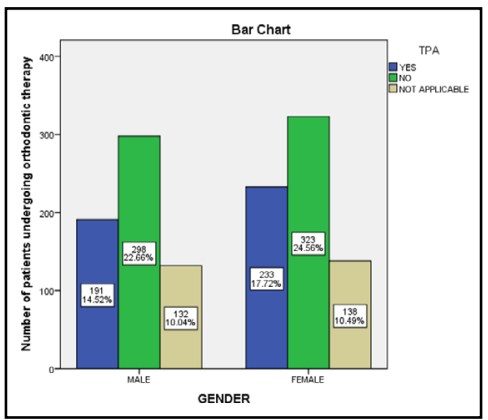

Graph 8. Bar graph represents the association between gender and the number of patients requiring LSA .X-axis represents the gender of the patients and Y-axis represents the number of patients requiring LSA during orthodontic therapy. Among the total study population, the majority of the patients requiring LSA were females as compared to male patients.

Chi square test,p value- $0.078>(0.05)$ hence, statistically not significant.

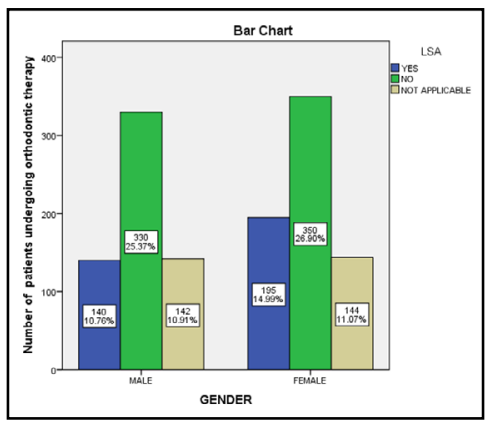


Graph 9. Bar graph representing the association between the number of patients requiring TPA and LSA. X-axis denotes the number of patients requiring TPA and Y-axis denotes the number of patients requiring LSA during an orthodontic treatment. The above graph shows that among the patients requiring TPA, $24.3 \%$ also required LSA. Chi square test, $p$ value $-0.00(<0.05)$ hence ,statistically significant.

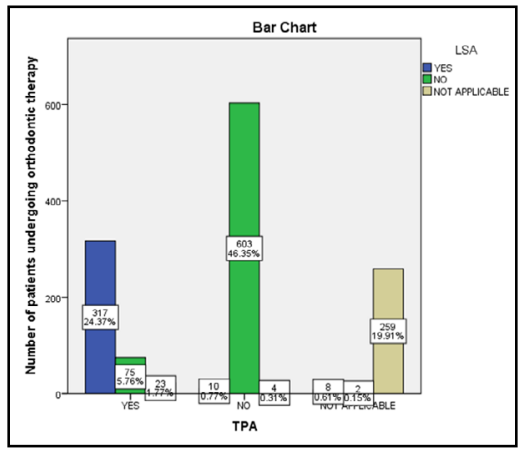

significantly increasing dental arch width and perimeter [9], and the changes remained stable after an average 6.7-year follow-up $[23,24]$. Although previous studies suggested that the adjunctive use of TADs should be significantly favored over the sole use of TPA as an anchorage device during retraction when properly indicated [6]. Results of previous studies show that TPA alone does not minimize anchorage loss when used with continuous arch mechanics due to the fact that different and unequal moments can be applied with TPA, as in cases of unilateral arch expansion [1]. Transpalatal arch poses the risk of coming close to the palatal tissue and getting embedded in the palatal tissue [27], hence the "U" loops can be adjusted by constriction of the loops to keep the transpalatal arch away from the palatal tissues [20]. Evaluation of growth pattern plays a major role in diagnosis and treatment planning [26].

The use of different types of transpalatal arches with different load-deflection rates renders it difficult to get accustomed to the amount of compensatory bends necessary for the desired tooth movement and should thus be avoided [3]. The medical profession has reused its metal instruments since the very beginning [15]. Transpalatal arch has been modified for different purposes. Low-placed transpalatal arch (TPA) is used in cases requiring molar intrusion but it may lead to indentations of the $\mathrm{U}$ loop on the dorsum of tongue, thus causing discomfort and irritation to the patient [21]. A study done on modifications of TPA [31] suggests that the modified TPA can be effortlessly removed and reactivated and can be converted to regular TPA once the desired expansion is achieved [10].

India is a large country, its inhabitant being multiethnic [8].This study is a retrospective study with a small number of cases. More prospective controlled clinical trials may be needed to confirm these results with a larger sample size and wide distribution of cases.

\section{Conclusion}

This study concludes that the frequency of TPA/LSA is more in females $(53 \%)$ than males $(47.2 \%)$, majority of the patients $(37 \%)$ belongs to the age group 21-30 years and that almost all patients requiring TPA (24.3\%) also required LSA (statistically significant). Transpalatal arches and Lingual stabilising arches are successful appliances in order to control the posterior sectors and improve the torsion of the molars. They allow the clinician in obtaining a more stable occlusion without the need for extra help from bone anchorage.

\section{References}

[1]. Alhadlaq A, Alkhadra T, El-Bialy T. Anchorage condition during canine retraction using transpalatal arch with continuous and segmented arch mechanics. Angle Orthod. 2016 May;86(3):380-5. Pubmed PMID: 26258898.

[2]. Almuzian M, Alharbi F, Chung LL, McIntyre G. Transpalatal, nance and lingual arch appliances: clinical tips and applications. Orthodontic Update. 2015 Jul 2;8(3):92-100.

[3]. Baldini G, Luder HU. Influence of arch shape on the transverse effects of transpalatal arches of the Goshgarian type during application of buccal root torque. Am J Orthod. 1982 Mar;81(3):202-8. Pubmed PMID: 6758595.

[4]. Bobak V, Christiansen RL, Hollister SJ, Kohn DH. Stress-related molar responses to the transpalatal arch: a finite element analysis. Am J Orthod Dentofacial Orthop. 1997 Nov;112(5):512-8. Pubmed PMID: 9387838.

[5]. Dahlquist A, Gebauer U, Ingervall B. The effect of a transpalatal arch for the correction of first molar rotation. Eur J Orthod. 1996 Jun;18(3):257-67. Pubmed PMID: 8791890.

[6]. Diar-Bakirly S, Feres MF, Saltaji H, Flores-Mir C, El-Bialy T. Effectiveness of the transpalatal arch in controlling orthodontic anchorage in maxillary premolar extraction cases: A systematic review and meta-analysis. Angle Orthod. 2017 Jan;87(1):147-158. Pubmed PMID: 27504820.

[7]. Dinesh SP, Arun AV, Sundari KK, Samantha C, Ambika K. An indigenously designed apparatus for measuring orthodontic force. J Clin Diagn Res. 2013 Nov;7(11):2623-6. Pubmed PMID: 24392423.

[8]. Felicita AS, Chandrasekar S, Shanthasundari KK. Determination of craniofacial relation among the subethnic Indian population: a modified approach - (Sagittal relation). Indian J Dent Res. 2012 May-Jun;23(3):305-12. Pubmed PMID: 23059564.

[9]. Felicita AS. Quantification of intrusive/retraction force and moment generated during en-masse retraction of maxillary anterior teeth using mini-implants: A conceptual approach. Dental Press J Orthod. 2017 SepOct:22(5):47-55. Pubmed PMID: 29160344.

[10]. Felicita AS. Orthodontic extrusion of Ellis Class VIII fracture of maxillary lateral incisor - The sling shot method. Saudi Dent J. 2018 Jul;30(3):265269. Pubmed PMID: 29942113.

[11]. Felicita AS. Orthodontic management of a dilacerated central incisor and partially impacted canine with unilateral extraction - A case report. Saudi Dent J. 2017 Oct;29(4):185-193. Pubmed PMID: 29033530.

[12]. Göllner P, Bantleon HP, Ingervall B. Force delivery from a transpalatal arch for the correction of unilateral first molar cross-bite. Eur J Orthod. 1993 Oct;15(5):411-20. Pubmed PMID: 8223976.

[13]. Ingervall B, Göllner P, Gebauer U, Fröhlich K. A clinical investigation of the correction of unilateral first molar crossbite with a transpalatal arch. Am J Orthod Dentofacial Orthop. 1995 Apr;107(4):418-25. Pubmed PMID: 7709907.

[14]. Jain RK, Kumar SP, Manjula WS. Comparison of intrusion effects on maxillary incisors among mini implant anchorage, $\mathrm{j}$-hook headgear and utility arch. J Clin Diagn Res. 2014 Jul;8(7):ZC21-4. Pubmed PMID: 25177631.

[15]. Kamisetty SK, Verma JK, Arun, Sundari S, Chandrasekhar S, Kumar A. SBS vs Inhouse Recycling Methods-An Invitro Evaluation. J Clin Diagn Res. 2015 Sep;9(9):ZC04-8. Pubmed PMID: 26501002.

[16]. Kecik D. Comparison of temporary anchorage devices and transpalatal arch- 
mediated anchorage reinforcement during canine retraction. Eur J Dent. 2016 Oct-Dec;10(4):512-516. Pubmed PMID: 28042267.

[17]. Krishnan S, Pandian S, Kumar S A. Effect of bisphosphonates on orthodontic tooth movement-an update. J Clin Diagn Res. 2015 Apr;9(4):ZE01-5. Pubmed PMID: 26023659.

[18]. Pandian KS, Krishnan S, Kumar SA. Angular photogrammetric analysis of the soft-tissue facial profile of Indian adults. Indian J Dent Res. 2018 MarApr;29(2):137-143. Pubmed PMID: 29652003.

[19]. Ramesh Kumar KR, Shanta Sundari KK, Venkatesan A, Chandrasekar S. Depth of resin penetration into enamel with 3 types of enamel conditioning methods: a confocal microscopic study. Am J Orthod Dentofacial Orthop. 2011 Oct;140(4):479-85. Pubmed PMID: 21967934.

[20]. Kumar ND, Krishna BR, Shamnur N, Mithun K. Modified transpalatal arch for molar intrusion. J Int Oral Health. 2014 Nov-Dec;6(6):88-9. Pubmed PMID: 25628492.

[21]. Mehta F, Patel R, Kharadi L, Mehta S. A modified transpalatal arch for correction of bucally placed maxillary 2nd molars: non-compliant mechanics. IOSR J Dent Med Sci. 2014;13(4):24-6.

[22]. Moutaftchiev V, Moutaftchiev A. The individually prepared transpalatal arch. Oral Hlth J. 2009;8:13-6.

[23]. Raucci G, Pachêco-Pereira C, Grassia V, d'Apuzzo F, Flores-Mir C, Perillo L. Maxillary arch changes with transpalatal arch treatment followed by full fixed appliances. Angle Orthod. 2015 Jul;85(4):683-9. Pubmed PMID: 25286341.

[24]. Raucci G, Elyasi M, Pachêco-Pereira C, Grassia V, d'Apuzzo F, Flores-Mir C, et al. Predictors of long-term stability of maxillary dental arch dimensions in patients treated with a transpalatal arch followed by fixed appliances. Prog Orthod. 2015;16:24. Pubmed PMID: 26215180.

[25]. Rebellato J. Two-couple orthodontic appliance systems: transpalatal arches. Semin Orthod. 1995 Mar;1(1):44-54. Pubmed PMID: 8935043.

[26]. Rubika J, Sumathi Felicita A, Sivambiga V. Gonial angle as an indicator for the prediction of growth pattern. World Journal of Dentistry. 2015;6(3):161-
3.

[27]. Samantha C, Sundari S, Chandrasekhar S, Sivamurty G, Dinesh S. Comparative Evaluation of Two Bis-GMA Based Orthodontic Bonding Adhesives - A Randomized Clinical Trial. J Clin Diagn Res. 2017 Apr;11(4):ZC40ZC44. Pubmed PMID: 28571259.

[28]. Shetty SK, Vigneshwaran AR, Kumar YM. Modification in transpalatal arch used in conjunction with a fixed twin block. Journal of Indian Orthodontic Society. 2019 Mar; 53(1):81-3.

[29]. Sivakumar N, Sundari KK, Chandrasekar S, Kumar MP. A review on smile arc-An orthodontist's perspective. Drug Invention Today. 2018 Sep 2;10.

[30]. Sivamurthy G, Sundari S. Stress distribution patterns at mini-implant site during retraction and intrusion--a three-dimensional finite element study. Prog Orthod. 2016;17:4. Pubmed PMID: 26780464.

[31]. Thomas A, Afshan T, Deru T. Modification of transpalatal arch for expansion. Journal of Indian Orthodontic Society. 2017 Dec;51(4):289-90.

[32]. Vikram NR, Prabhakar R, Kumar SA, Karthikeyan MK, Saravanan R. Ball Headed Mini Implant. J Clin Diagn Res. 2017 Jan;11(1):ZL02-ZL03. Pubmed PMID: 28274084.

[33]. Viswanath A, Ramamurthy J, Dinesh SP, Srinivas A. Obstructive sleep apnea: awakening the hidden truth. Niger J Clin Pract. 2015 Jan-Feb;18(1):1-7. Pubmed PMID: 25511335.

[34]. Wise JB, Magness WB, Powers JM. Maxillary molar vertical control with the use of transpalatal arches. Am J Orthod Dentofacial Orthop. 1994 Oct;106(4):403-8. Pubmed PMID: 7942656

[35]. Yañez-Vico RM, Perula MCL, Solano-Reina E. Vertical and Transverse Management with Transpalatal Arches in an Adult with Class III Malocclusion. Case Rep Dent. 2017;2017:4062105. Pubmed PMID: 28642827.

[36]. Zablocki HL, McNamara JA Jr, Franchi L, Baccetti T. Effect of the transpalatal arch during extraction treatment. Am J Orthod Dentofacial Orthop. 2008 Jun;133(6):852-60. Pubmed PMID: 18538249. 